\title{
ARTICLES
}

\section{DESCRIPTION OF ATTITUDE OF MOTHERS REGRADING EXPRESSION OF BREAST MILK AND STORAGE AMONG WORKING MOTHERS OF INFANT IN SELECTED PRIMARY HEALTH CENTRES OF TAMILNADU}

\author{
Mr. Sugumar. S*| Dr. Raja A** \\ *Professor, National Institute of Health Education \& Research, Patna, Bihar, India. \\ **Principal, Unity Academy of Education, Mangalore, India. \\ DOI: http://doi.org/10.47211/trr.2019.v05i02.016 \\ Received $22^{\text {th }}$ November 2019, Accepted $10^{\text {th }}$ December 2019, Published $20^{\text {th }}$ December 2019
}

\begin{abstract}
Breastfeeding is the organic standard for all well evolved creatures, including people. Breastfeeding is basic for accomplishing worldwide objectives on sustenance, wellbeing and endurance, financial development and ecological supportability. When a mother thinks that she does not have enough breast milk, her baby is in fact getting all that the needs. The study was carried out to assess the Attitude of mothers of Infant regarding expression of Breast Milk. Quantitative approach and descriptive design was adopted for this study. Data was collected from 600 mothers by using convenient sampling technique whoever meets inclusion and exclusion criteria. Results were interpreted and it was found that in terms of attitude, 50\% of samples had favorable and moderately favorable attitude. The study concludes that Health education programs, workshops, pamphlets and counseling can be modified as video assisted teaching, demonstration and observation with constant follow up.
\end{abstract}

Key Words: Attitude, breastfeeding, mother, breast milk, baby.

ABOUT AUTHORS:

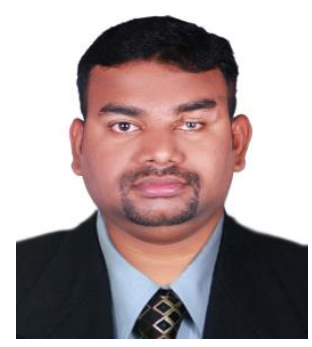

The author Mr. Sugumar. S is Professor in National Institute of Health Education \& Research, Patna, Bihar, India.

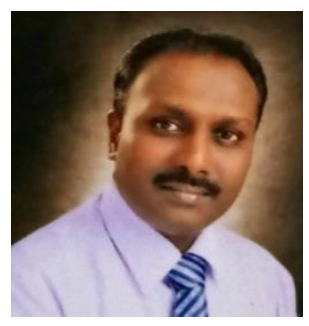

The author Dr. Raja A is Principal at Unity Academy of Education, Mangalore, India. He has published research articles in various national and International journals. 


\section{INTRODUCTION}

Insufficient breastfeeding rehearses fundamentally hinder the wellbeing, advancement and endurance of babies, youngsters and moms. Human milk banks gather, screen, purify, and circulate gave bosom milk to clinics or outpatient beneficiaries. Typically the assortment, stockpiling, and preparing in a human milk bank follows set up rules. Milk banks are by a wide margin the most significant suppliers of benefactor milk, the reality not withstanding that different scenes of milk gift are additionally utilized. The fundamental capacity of milk banks is to fill in as archives of gave milk so it is accessible when required. Milk banks get milk from givers, measure it, and store it until utilized. Most regularly milk from various contributors is pooled, albeit a few banks pool milk just of individual benefactors (single-giver banks). Typically, milk gave by milk banks has gone through sanitization. The first two HMBs were opened In Ireland by the Ministry of Health (MoH), in partnership with A\&T and others, in Viet Nam at Da Nang Hospital for Women and Children (2017) and Tu Du Hospital (2019). (Alive\& Thrive, 2019)

A study was conducted to assess the Knowledge, Attitude and Practice of Expression of Breast Milk among 95 Mothers in Western Maharashtra. Result of their study, the analysis has indicated that every mother was not aware of the methods of breast milk expression. Correct knowledge about EBM was present in 89 (93.7\%) participants; correct knowledge about technique of milk expression and storage of expressed breast milk was present in 17 (17.9\%) and 34 (35.7\%) of study participants. The prevalence of Breast milk expression was $17.9 \%$. Most common cause for it was to relieve breast tenderness. They concluded as Breast milk expression should be promoted to avail its full benefits. Proper technique should be taught during ANC clinics. (Dr. Priya Mohan Prabhu et. al., 2014) Every year in India more than 1,000,000 babies bite the dust before they complete their first month of life, representing $30 \%$ of the world's neonatal passing. Very nearly one in each three children on the planet, who bite the dust before they are a month old, is in India. India's present neonatal death pace of 44 for every 1000 live births speaks to 1.2 million kids who pass on every year. Neonatal mortality is higher in country zones at 49 for each 1000 live births versus 27/1000 in metropolitan territories. (SOWC, 2019)

An examination was directed for 597 moms to assess the impact of specific variables on the length of selective bosom taking care of during the initial a half year of life. Complete information were gotten until half year. At release, one month, multi month and a half year, the much of the time of selective bosom taking care of was $97.5 \%, 83 \%$, and $56 \%$ and $19 \%$ individually. A bigger span of restrictive bosom taking care of was essentially connected with positive maternal mentalities towards bosom taking care of, satisfactory family uphold, suitable sucking strategies and no areola problems. (Robert Rebar, 2018)

The neonatal death rate additionally fluctuates extensively among Indian states. Tamilnadu would come next with a neonatal mortality of over 40 for each thousand live births. Orissa and Madhya Pradesh have the most elevated neonatal death paces of 61 (rustic 63, metropolitan 42) and 59 (country 63, metropolitan 40) per 1000 live births, individually. In Uttar Pradesh the rate is 53/1000 (rustic 56, metropolitan 39), and 31/1000 (country 33, metropolitan in West Bengal. Kerala has the most minimal neonatal mortality of 10/1000((rural 10, metropolitan 9), trailed by Punjab 29/1000 (country 32, metropolitan 19). (MJ Sankar et.al., 2016). It was found that the essential requirement to re-establish EBM practice in southern part of India. There are plenty of studies done regarding breast feeding all over India. Some studies covered breast feeding practices commonly. But very few studies concentrated on Expression of Breast Milk and its Storage. Those studies were taken lesser than 100 samples and it was done among the mothers in hospital setting. Also very few studies conducted in the state of Tamilnadu. So it is going to assess the attitude of EBM as an initial stone print.

\section{Statement of the Problem}

\section{"Attitude on Expression of Breast Milk and Storage among working mothers of Infant in selected Primary Health Centres of Tamilnadu". \\ Objectives}

1. To assess the Attitude on EBM and Storage among working mothers of Infant

\section{METHODOLOGY}

\section{Research Approach}

Quantitative research approach was considered as an appropriate one for the present study.

\section{Research Design}

Descriptive design helps to explain the attitude about EBM and its storage. 


\section{ARTICLES}

\section{Setting of the Study}

The present study was conducted in five Primary Health Centers such as Kanniseripudur, Amathur, Avudaiyapuram, Alagapuri and Sengundrapuram under Virudhunagar Block, Virudhunagar District, Tamilnadu state. Kanniseripudur is considered as a main PHC and other four PHCs meant for implementation of the planning done by Kanniseripudur.

\section{Population}

The accessible population of the present study was working mothers who were having infants in selected primary health centre in virudhunagar district, Tamilnadu.

\section{Sample}

The sample selected for the present study was the mothers who were visiting OPD and met inclusion and exclusion criteria at selected primary health centre in virudhunagar district, Tamilnadu.

\section{Sample Size}

The total sample size was 600 working mothers who were having infant at selected Primary health centers

\section{Sampling Technique}

The researcher found convenient sampling technique was an appropriate one to pick out the mothers from available location since it has different number of population.

\section{DISCUSSION}

Table 1: Attitude on EBM and Storage among working mothers of Infant

\begin{tabular}{|c|c|c|c|c|c|c|c|c|}
\hline $\begin{array}{c}\text { Sl. } \\
\text { No }\end{array}$ & Aspect & Max score & Mean & Range & Median & SD & Mean \% & SE \\
\hline 1 & Attitude & 100 & 69.54 & $57-83$ & 69 & 4.99 & 69.54 & 0.20 \\
\hline
\end{tabular}

Table No. 1 describes the attitude levels of mothers regarding expression of breast milk, the mean percentage of attitude score was $59.54 \%$ with mean and SD of attitude score was $69.54 \pm 4.99$. The standard error was 0.20 and median was 69.

Table 2: Classification of mothers based on levels of attitude

\begin{tabular}{|c|l|c|c|}
\hline S. No & \multicolumn{1}{|c|}{ Categories } & Frequency & Percentage \\
\hline 1 & $\begin{array}{l}\text { Unfavorable attitude } \\
<35 \%\end{array}$ & 00 & 00 \\
\hline 2 & $\begin{array}{l}\text { Moderately Favorable attitude } \\
35 \%-70 \%\end{array}$ & 299 & 49.83 \\
\hline 3 & $\begin{array}{l}\text { Favorable attitude. } \\
>70 \%\end{array}$ & 301 & 50.16 \\
\hline
\end{tabular}

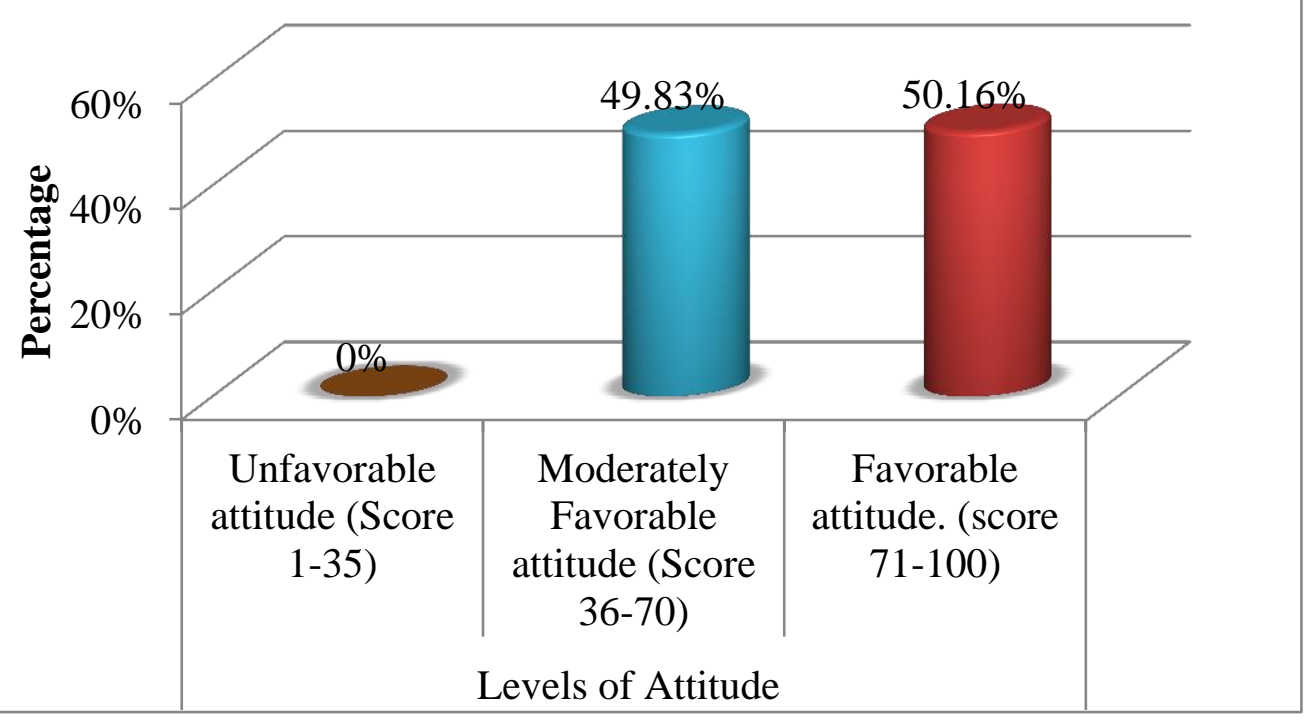

Figure .1: Percentage distribution of mothers according to level of attitude

Table No 2 and Figure 1 describes the respondents classification based on attitude levels, 299(49.83\%) were had moderately favorable attitude and 301(50.16\%) were had favorable attitude. 
Attitude levels of mothers regarding expression of breast milk were the mean percentage of attitude score was $59.54 \%$ with mean and SD of attitude score was $69.54 \pm 4.99$. The standard error was 0.20 and median was 69 . The respondents classification based on attitude levels, 299(49.83\%) were had moderately favorable attitude and $301(50.16 \%)$ were had favorable attitude. No mothers had unfavorable attitude.

\section{These findings probably due to,}

$>$ Misconceptions has been unfastened from society regarding colustrum or breast milk

$>$ Wise practice and low errors of EBM evidenced until a generation before

$>$ Breast milk was used for some eye infections of adult strengthen public opinion

S Rai (2017) on her Expressed breast milk: a less used option by working mothers of India, proved regarding attitude that, out of 100 working mothers with infants less than one year, 60(60\%) of them had positive and 40 (40\%) of them had negative attitude. She compared attitude with other two variables i.e. knowledge and practice that, knowledge about expressed breast milk feeding in Indian working breastfeeding mothers is suboptimal and imparting adequate knowledge can improve feeding practices. But major attitude was positive.

MAJOR FINDINGS

Attitude levels of mothers regarding expression of breast milk were the mean percentage of attitude score was $59.54 \%$ with mean and SD of attitude score was $69.54 \pm 4.99$. The standard error was 0.20 and median was 69 . The respondents classification based on attitude levels, 299(49.83\%) were had moderately favorable attitude and $301(50.16 \%)$ were had favorable attitude. No mothers had unfavorable attitude.

\section{CONCLUSION}

Nurses play an important role in reducing the rate of neonatal mortality and morbidity through teaching postnatal mothers regarding methods of EBM. The study concludes that the mothers who were having deficiency of practice can be compensated by movement of the initiatives from government and NGOs from theory to practice. Health education programs, workshops, pamphlets and counseling can be modified as video assisted teaching, demonstration and observation with constant follow up.

\section{REFERENCES}

1. Burroughs (2001), "Maternity Nursing an Introduction Text", 7th edition, W.B. Saunders Company, London. Living stons private limited.

2. Collin, W.B., Scott, J.A., (2002) "Breast feeding reasons for starting, and problems along the way breast feed Review", Journal Human Lactation (10) (2), 13-17.

3. Dewan, N., Wood.L. (2002), "Breast feeding knowledge and attitudes of teenage mothers in Liverpool' 'Journal of Human nutrition diet, 15(1), 33-37.

4. UNICEF, India [Online] [Cited 2 March 2010]. Available from: URL:http://www.unicef.org/infobycountry/india_statistics.html.

5. Priva Mohan Prabhu, Radhe BK, Jayashree Dayanad Naik, Tanuja Ravindra Brahmankar, Vivek Shivaji rao Behere (2016), "A study to assess the knowledge, attitude and practice of Expression of Breast milk among mothers in western Maharashtra", Journal of Medical Science and Clinical Research (JMSCR), Vol-4, Issue1, January 2016, Pp - 8828-8834, DOI: http://dx.doi.org/10.18535/jmscr/v4i1.07.

6. Katusiime R., (2016) “Knowledge, attitude and practice of expressed breast milk feeding among working mothers of infants aged 0-6 months attending maternal child health clinic at upper Mulago National Referral Hospital, Kampala District". Available at http://catalog.ihsu.ac.ug:8585/cgibin/koha/opacdetail.pl?biblionumber $=6431$ 